\title{
Study of external and internal injuries to the neck structure in cases of hanging
}

\author{
Anil Kumar Yadav', Virender Chhoker², Kaushal Kishore³, Yogesh Yadav,"* \\ ${ }^{1}$ Resident, ${ }^{2}$ Professor and Head, ${ }^{3}$ Associate Professor, ${ }^{4}$ Professor, ${ }^{1-3}$ Dept. of Forensic Medicine \& Toxicology, ${ }^{4}$ Dept. of \\ Anatomy, Santosh Medical College \& Hospital, Ghaziabad, Uttar Pradesh, India
}

*Corresponding Author:

Email: yogeshyadav@msn.com

\begin{abstract}
Introduction: Asphyxia could occur in various situations like: Traumatic asphyxia, Hanging, Choking, Smothering, Strangulation, poisoning, etc. There are both external and internal general features to diagnose fatal asphyxia macroscopically such as: a) External (i) ligature mark (ii) congestion, cyanosis \& petechial hemorrhages. b) Internal - fluidity of blood, dilatation of right chamber of heart and visceral congestion.

Materials and Methods: An observational Cross sectional study was carried out in Department of Forensic Medicine \& Toxicology, Santosh Medical College, Ghaziabad. A total 58 cases of fatal neck compression were included in this study during. All the cases with alleged history of fatal neck compression were included in the study, except where the dead body was severely decomposed, that would effect the observation of findings. In study the aim was to find out the different associated lesions, injuries / fracture of the organo-complex of the larynx, bleeds in the tongue, hemorrhage in the tonsils and tonsilar beds.

Results: Majority cases of hanging were seen in young adult age group of $20 \pm 30$ years. The overall male : female ratio in cases of hanging was 11:1. Majority cases of hanging were suicidal. Neck compression and hanging were seen between time interval of $6+\mathrm{AM}$ to 12 noon. Congestion of the face was observed in 60.86\%. Hemorrhage in Sub-conjunctiva, strap muscle, tongue, epiglottis and tonsil were seen in 13\%, 23.91\%, $13.04 \%, 20 \%$ and $15.21 \%$ cases respectively. Hyoid bone fracture was present in $13.04 \%$ while thyroid cartilage fracture was present in $4.34 \%$.

Conclusion: According to the present study hanging is more common in young adults mostly suicidal in nature. congestion of face is most significant external feature in hanging while tonsillar heamorrage is significant internal feature.
\end{abstract}

Keywords: Hanging, Asphaxia, External neck injury, Internal neck injury, Ligature mark.

\section{Introduction}

The term "asphyxia"is originally from Greek, means absence of pulsation ${ }^{1}$ but commonly understood to mean, "lack of oxygen". Asphyxia could occur in various situations like: Traumatic asphyxia, Hanging, Choking, Smothering, Strangulation, poisoning, etc. Asphyxial deaths have worldwide distribution. The incidence of asphyxia varies in different part of the world, so does the sexual pattern, mode and manner of causation. In parts of United Kingdom some $90 \%$ of suicides are due to hanging. ${ }^{2}$ In Oslo and Copenhagen capital areas, $22 \%$ of all homicides were due to asphyxia and $73 \%$ of all these victims were females. ${ }^{3}$ Over the past years, $7.4 \%$ of deaths caused by strangulation in Peoria County, involved children less than 18 years of age. ${ }^{4}$ In Imphal (India) among 142 cases of violent asphyxial deaths during the 5-year period (1992-1996), hanging (43\%) was the commonest type followed by drowning (34.5\%), strangulation (9.9\%) and traumatic asphyxia (5.6\%). ${ }^{5}$ According to an epidemiological study conducted in the department of forensic medicine, University College of medical sciences, during the 10-year period from 1993-2002, the incidence of violent asphyxia was $8.15 \%$ in the east Delhi. $^{6}$

Hanging which is defined as asphyxia is due to compression or constriction of the neck structures by noose or others constricting band tightened by the weight of the body ${ }^{7}$ is one of the commonest method of committing suicide. In hanging the subcutaneous tissue below the ligature mark is usually dry, white and glistening. There may be petechial hemorrhages in the adjutant tissues above and below the ligature mark and bruising in the subcutaneous tissues and the muscles deep to the mark. Hemorrhages may be seen around the fractured bone and cartilages. However still in some cases a forensic expert may face challenge to differentiate between the mode and the manner of asphyxia. Thus injury to cricoarytenoid internal examination of neck and its findings can definitely give a clue towards proper diagnosis. there are no universally recognized pathognomic signs of asphyxia, but pathologists frequently make this diagnosis based on observations that individually have indeterminate significance but combined together, in the appropriate context, have diagnostic value. Hemorrhages restricted to the margins of the tongue can be found not infrequently in several types of death and result probably in most instances from mechanical compression by the teeth. ${ }^{8}$ Sometimes a specific order of gross hemorrhages inside the tongue indicates an impression injury by the hyoid bone into the tongue. ${ }^{9}$ The only clinical criteria that can help in distinguishing is the position and shape of the ligature on the neck, which in the cases of hanging is inverted ' $\mathrm{V}$ ' shaped, 
above the level of thyroid cartilage, and discontinuous at times.

The classic sign of asphyxia are mentioned as congestion, cyanosis, edema, and petechiae above the line of constriction in cases of violent neck compression. The external jugular system is most vulnerable, and any superficial pressure encircling the neck will also obliterate the lumen of external jugular system causing a rapid rise in venous pressure in the head, especially if the carotid artery is still patent, which is usually the case. ${ }^{10}$ The face frequently appears swollen and bloated and following strangulation because fluid leaks out of blood vessels and results in edema. The pin point petechail hemorrhages are seen over the sclera, the mucous membrane insight the lips, around and behind the ears and auricles. They may also be found all over the facial skin either isolated in groups or confluent. Their size ranges from a $10^{\text {th }}$ of a millimetre upto 2 millimetre or occasionally even larger. These petechial hemorrhages arise in thin walled venules as a result of sudden rise in inner pressure leading to overextension and rupture and are influenced mainly by four pathogenetic factors. (1) engorgement of the veins caused by restricted outflow accompanied by uninterrupted arterial inflow (2) endothelial damage caused by oxygen deficiency, (3) hypertensive episodes in conclusive phase (4) local effects such as suction or pressure in defined areas. ${ }^{1}$

\section{Materials and Methods}

An observational cross-sectional study was condected in department of Forensic Medicine, Santosh Medical College, Ghaziabad from Jan. 2015 to Dec. 2016. Ethical clearance was taken from the Institutional Ethical Committee. A total 58 cases of fatal neck compression were included in this study during. All the cases with alleged history of fatal neck compression were included in the study, except where the dead body was severely decomposed, that would effect the observation of findings.

External Examination: A thorough external examination of the body was carried out with special emphasis on the examination of face \& neck. It include: Inspection - noting the color, site \& extant of ligature mark/pressure abrasion. Also the other cardinal feature of asphyxia, like petechial spots on face and conjunctiva, congestion of face, cyanosis, postmortem staining (color, position \& extent).

Palpation-noting the texture of ligature mark/pressure abrasion and feeling for any crepitus over laryngeal apparatus.

Internal Examination: The autopsy was conducted using standard 'I' shaped method, opening all the 3 body cavities. The organs from cranial and chest cavity were removed first using Virchow's method and then the neck dissection was performed. Larynx and a small portion of trachea dissected out from the body after a separate layer-by-layer dissection of neck following removal of the brain and viscera. The incidence of the fractures of hyoid bone and thyroid cartilage if any and its association with these hemorrhages to the neck structure were noted. Sections of the fixed larynx was then embedded in the paraffin in toto and processed for hematoxylin- eosin staining and was examined under microscope to look for sub hemorrhages.

Data collection and entry was done using the microsoft excel sheet and statistical analysis was done in relation to different parameters using SPSS (trial version).

\section{Results and Discussion \\ Manner of Asphyxia}

Out of the total 58 cases of death due to neck compression, $79.3 \%$ were due to hanging, while rest were due to strangulation. This is again in the same pattern as studied by Lalwani and others ${ }^{[11]}$. Meaning thereby that hanging is a popular method of committing asphyxial deaths because it can be accomplished easily and does not require any special paraphernalia. Secondly, it is also considered as least painful death and commonly shown in the media. In hanging, a vast majority $(97.8 \%)$ were suicidal. This is again in tune with already existing literature that usually labels hanging as suicidal and state that a death by hanging should be regarded as suicide unless proved otherwise. $^{12}$

Age: The age of the cases in the present study varied between 13-82 years, with mean age of $27.90 \pm 10.66$ years, while in cases of hanging the minimum age was found as 13 years and maximum 48 years with mean age of $26.09 \pm 7.61$ years (Table 1).

These results are in consonance with the long-term study in Cardiff that also described the age range in his study as $2^{\text {nd }}$ to $9^{\text {th }}$ decade. ${ }^{13}$ As per Morild. ${ }^{14}$ who studied the cases of suicidal hanging, and he found average age of his cases slightly higher at 38.7 years. Similarly, Simonson ${ }^{15}$ also studied cases of hanging found the average age among females as 52 years with a range of 13-83 years and among males 53 years with a range of 10-89 years. The mean age in the present study was on the lower side, thereby suggesting that more of the young people are involved in such deaths in comparison to the studies from the West. However, this age is in tune with the similar study from Delhi. ${ }^{11}$

Sex: The overall male:female ratio in cases of hanging, it was 11:12. It is again in tune with somewhat similar observation in a study from Southern part of the city ${ }^{[11]}$ as well as from South Africa. ${ }^{12}$ However, some studies from west have shown contrasting trend of female dominance among the cases of homicidal asphyxia. ${ }^{3}$ This variation may be due to geographical and suicidal variation in the involvement of victims in the crime. 
Time of Incident: Most of the hanging among males $(45.5 \%)$ were again seen in the period between $6+\mathrm{AM}$ to 12 noon, while the similar percentage among the females i.e. $45.8 \%$ was seen in during $12+$ noon to 6 $\mathrm{PM}$. The figure appears to have significant difference in both the groups.

Survival Time: Most of the cases (87.9\%) in our study were spot death. Of the remaining who survived for some time, 2 were cases of hanging, 1 case, who survived for $<12$ hours was a female of 17 years of age and the another who survived for $>12$ hours was a male of 40 years of age.

Crepitus: As suggested by Hanson ${ }^{16}$ an attempt was made to palpate the larynx and feel for the crepitus when the larynx is moved from side to side with slight posterior pressure. No appreciable absence of crepitus was noticed that might be due to fatal nature of cases in the present study and thereby fixing the larynx through rigor mortis of the neck.

External Findings (Table-2): In the present study, the congestion of face was observed in $>50 \%$ of cases, while the congestion in and around ear was found in $>15 \%$ cases. The sub-conjunctival petechial hemorrhages in about $1 / 4^{\text {th }}$ of all cases.

In hanging, different authors over the years have reported different frequency of facial congestion; Simonsen $(52.2 \%)^{15}$ and James $^{13} \quad(5 \%)$, while Samarasekra ${ }^{17}$ reported presence of subconjunctival petechial hemorrhages in $48 \%$ cases in hanging.

\section{Internal Findings (Table-3)}

Strap Muscle Hemorrhages: The strap muscle hemorrhage was found in $23.9 \%$ cases. The prevalence of these hemorrhages which is in accordance as reported in cases of hanging in the literature which reports their presence in hanging varying from 2-38\%. ${ }^{18}$

Tongue hemorrhage: Recently a lot of work is being done on tongue hemorrhage and their importance in differentiating different types of mechanical asphyxia. The earliest published work on this issue was conducted by Suyama ${ }^{8}$ and others that consider hemorrhage in central part of the tongue as a sign of severe asphyxial deaths. The reported figure of tongue bleeding in the literature in cases of suicidal hanging ranging from 0 $14 \% .{ }^{19}$

In the present series, the frequency of tongue hemorrhage was $13.04 \%$, similar to the finding reported earlier. Majority of tongue hemorrhages were observed at the base of the tongue and were grade 2 in size.

Tonsilar hemorrhage, Epiglottic hemorrhage and Vocal fold hemorrhage: The lining of the larynx and pharynx, also are the sites of acute hemorrhages in cases of neck compression. At times these hemorrhages are extensive, flame shaped and are frequently found inferior to vocal cords. ${ }^{[16]}$ In the present study, the tonsilar hemorrhages were seen in $12 \%$ of all cases. Epiglottic hemorrhages were quite infrequently in only $8.6 \%$ cases. Similarly, vocal fold haemorrhages were found only in about $5 \%$ cases.

Hyoid bone and thyroid cartilage fractures: Quite a large number of workers have worked on the issue of fracture of hyoid bone and thyroid cartilage in compression of neck and has great appeal as to the diagnostic criteria for neck compression for two main reasons:

1. It is an objective and impressive gross autopsy finding.

2. Can be clearly related to the mechanical injury to the neck.

But the incidence of laryngeal fracture has exceeded $50 \%$ in some studies. Fractures of hyoid bones are usually found in posterior third of the greater cornu, may be unilaterally or bilaterally and local hemorrhage is found at the site of discontinuity.

The overall incidence of hyoid bone and thyroid cartilage fracture in the present study was found $17.2 \%$ and $10.3 \%$ respectively. The incidence of hyoid bone and thyroid cartilage fractures in hanging was $13.04 \%$.

Table 1: Age distribution in Hanging

\begin{tabular}{|c|c|c|}
\hline S. No. & Age group (yrs) & Hanging N (\%) \\
\hline 1 & $1-10$ & 0 \\
\hline 2 & $10-20$ & $10(21.73 \%)$ \\
\hline 3 & $20-30 \mathrm{r}$ & $27(58.69 \%)$ \\
\hline 4 & $30-40$ & $7(15.2 \%)$ \\
\hline 5 & $40-50 \mathrm{yr}$ & $2(4.34 \%)$ \\
\hline 6 & $>50 \mathrm{yr}$ & 0 \\
\hline \multicolumn{2}{|c|}{ Total } & $46(100)$ \\
\hline
\end{tabular}

Table 2: External findings in Hanging

\begin{tabular}{|c|c|c|c|c|c|}
\hline \multirow[t]{3}{*}{ S. No. } & \multirow{3}{*}{$\begin{array}{c}\text { Age group } \\
\text { (Yrs) }\end{array}$} & \multicolumn{4}{|c|}{ Hanging $(n=46)$} \\
\hline & & \multirow{2}{*}{$\operatorname{Sex}(M / F)$} & \multirow{2}{*}{ Subconj. Hemg } & \multicolumn{2}{|c|}{ Congestion } \\
\hline & & & & Face & Ear \\
\hline 1 & $1-10$ & $0 / 0$ & 0 & 0 & 0 \\
\hline 2 & $10-20$ & $2 / 8$ & $3(50 \%)$ & $5(17.85 \%)$ & $2(22.22 \%)$ \\
\hline
\end{tabular}




\begin{tabular}{|c|c|c|c|c|c|}
\hline 3 & $20-30$ & $13 / 14$ & $3(50 \%)$ & $18(64.28 \%)$ & $4(44.44 \%)$ \\
\hline 4 & $30-40$ & $6 / 1$ & 0 & $3(10.7 \%)$ & $1(11.11 \%)$ \\
\hline 5 & $40-50$ & $1 / 1$ & 0 & $2(7.1 \%)$ & $2(22.22 \%)$ \\
\hline 6 & $>50$ & $0 / 0$ & 0 & 0 & 0 \\
\hline \multicolumn{2}{r}{ Total } & $\mathbf{2 2 / 2 4}$ & $\mathbf{6}$ & $\mathbf{2 8}$ & $\mathbf{9}$ \\
\hline
\end{tabular}

Table 3: Internal Tongue and Neck findings in Hanging

\begin{tabular}{|c|c|c|c|c|c|c|c|c|}
\hline $\begin{array}{c}\text { Age Group } \\
(\mathbf{y r s})\end{array}$ & $\begin{array}{c}\text { Male / } \\
\text { Female }\end{array}$ & $\begin{array}{c}\text { Strap Muscle } \\
\text { Hmg }\end{array}$ & $\begin{array}{c}\text { Epiglottic } \\
\text { Bleed }\end{array}$ & $\begin{array}{c}\text { Vocal Fold } \\
\text { Hmg }\end{array}$ & $\begin{array}{c}\text { Hyoid } \\
\text { Fracture }\end{array}$ & $\begin{array}{c}\text { Thyroid } \\
\text { Cartilage } \\
\text { Fracture }\end{array}$ & $\begin{array}{c}\text { Tongue } \\
\text { Bleed }\end{array}$ & $\begin{array}{c}\text { Tonsilar } \\
\text { Bleed }\end{array}$ \\
\hline $1-10$ & $0 / 0$ & 0 & 0 & $1(50 \%)$ & 0 & 0 & 0 & 0 \\
\hline $10-20$ & $2 / 8$ & $2(18.2 \%)$ & $1(100 \%)$ & 0 & $3(50 \%)$ & 0 & $1(16.7 \%)$ & $2(28.6 \%)$ \\
\hline $20-30$ & $13 / 14$ & $6(54.5 \%)$ & 0 & $1(50 \%)$ & $2(33.3 \%)$ & $1(50 \%)$ & $4(66.7 \%)$ & $4(57.1 \%)$ \\
\hline $30-40$ & $6 / 1$ & $1(9.09 \%)$ & 0 & 0 & 0 & $1(50 \%)$ & $1(16.7 \%)$ & $1(14.3 \%)$ \\
\hline $40-50$ & $1 / 1$ & $2(18.2 \%)$ & 0 & 0 & $1(16.7 \%)$ & 0 & 0 & 0 \\
\hline$>50$ & $0 / 0$ & 0 & 0 & 0 & 0 & 0 & 0 & 0 \\
\hline Total & $\mathbf{2 2 / 2 4}$ & $\mathbf{1 1}$ & $\mathbf{1}$ & $\mathbf{2}$ & $\mathbf{6}$ & $\mathbf{2}$ & $\mathbf{6}$ & $\mathbf{7}$ \\
\hline
\end{tabular}

\section{Conclusion}

Majority cases of hanging were seen in young adult age group of $20 \pm 30$ years. The overall male:female ratio in was 11:12. Majority cases of hanging were suicidal. Maximum cases of hanging were seen between time interval of $6+\mathrm{AM}$ to 12 noon. Maximum number of child, adolescents and young adult hangings were seen between the time of interval of $12+$ midnight to 12 noon. Most male hangings occurred between the time interval of $6+\mathrm{AM}$ to 12 noon, while most female hangings occurred between the time interval of $12+$ noon to $6 \mathrm{PM}$. Congestion of the face was observed in $60.86 \%$, ear congestion was seen in 9 cases of hanging and sub-conjunctival hemorrhages were seen in $13 \%$ cases of hanging strap muscle hemorrhage was found in $23.91 \%$ cases. A high percentage $(54.54 \%)$ of cases of strap muscle hemorrhage belong to age group of $20 \pm$ 30 years in hanging. Tongue hemorrhage was found in $13.04 \%$ cases in hanging. Tonsillar hemorrhage was seen in 7 cases (15.21\%), Epiglottic hemorrhage was seen $20 \%$. Hyoid bone fracture was present in $13.04 \%$ while Thyroid cartilage fracture was present in $4.34 \%$.

\section{References}

1. James P (ed). Forensic Medicine - Clinical and Pathological Aspects. London: Greenwich Medical Ltd. 2003:261.

2. Mason JK. The Pathology of Violent Injury. London: Edward Arnold. 1978;81.

3. Rogde S, Hougen HP, Poulsen K. Asphyxial homicide in two Scandinavian capitals. Am J Forensic Med Pathol. 2001;22(2):128-33.

4. Sabo RA, Hanigan WC, Flessner K, Rose J, Aaland M. Strangulation injuries in children. Part 1. Clinical analysis. J Trauma. 1996;40(1):68-72.

5. Momanchand A, Devi M, Flimate L. Violent asphyxial deaths in Imphal. J Forensic Med Toxicol. 1998;15:6064.
6. Verma SK, Lal S. Strangulation deaths during 1993-2002 in East Delhi (India). Leg Med (Tokyo). 2006;8:1-4.

7. J, Di Maio JM. Asphyxia. In: Dominick J, DiMaio JM (eds), Forensic Pathology. New York: Elsevier; 1989:223-224.

8. Suyama H, Nakasono I, Yoshitake T, Narita K, Yoshida C. Significance of haemorrhages in central parts of the tongue found in the medicolegal autopsy. Foren Sci Int. 1982;20(3):265-68.

9. Sperry K. An unusual, deep lingual hemorrhage as a consequence of ligature strangulation. J Forensic Sci. 1988;33(3):806-11.

10. Knight B. Forensic Pathology, $2^{\text {nd }}$ ed. London: Arnold. 1996: 361-78.

11. Lalwani S, Sharma AK, Rautji R, Bhardwaj DN, Dogra TD. Pattern of violent asphyxial deaths in Southern Delhi - a retrospective study. Ind Med Gazette. 2004;258-61.

12. Scribarte L, Bumental R, Saayman G, Roos JL. A retrospective review of 1018 suicide cases from the capital city of South Africa for the period 1991-2000. Am J Forensic Med Pathol. 2004;25:52-55.

13. James RYK, Silcocks P. Suicidal hanging in Cardiff--a 15-year retrospective study. Forensic Sci Int. 1992;56(2):167-75.

14. Morild I. Fractures of neck structures in suicidal hanging. Med Sci Law. 1996;36(1):80-84.

15. Simonsen J. Patho-anatomic findings in neck structures in asphyxiation due to hanging: a survey of 80 cases. Forensic Sci Int. 1988;38(1-2):83-91.

16. Hanson SH. Laryngeal crepitus: an aid to diagnosis in non-fatal strangulation. Med Sci Law. 2001;41:284-86.

17. Samarasekra A, Cook C. The pathology of hanging deaths in Western Australia. Pathology. 1996; 28(4):33438.

18. Boven BA. Hanging: A review. Forensic Sci Int. 1982;20:247-49.

19. Maxeiner $\mathrm{H}$, Bockholdt B. Hemorrhages in tongue in post-mortem diagnostics of strangulation. Forensic Sci Int. 2002;126:214-20. 